\title{
IN MEMORIAM Tomás Quesada Quesada (Huelma (Jaén), 1958 - Granada, 1996)
}

Durante más de una década he mantenido con Tomás Quesada una relación que iba más allá del trabajo. Por eso, cuando Vicente Salvatierra, director de esta revista, amigo y compañero de ambos, me sugirió hacer su In memoriam, me pareció no un deber inexcusable, sino una verdadera necesidad personal. Nunca he sufrido tanto como ahora al escribir unas páginas. Durante bastante tiempo quedé paralizado, tal como si una bomba hubiese estallado muy cerca y no pudiera reaccionar. En mis recuerdos siempre aparecía la fría mañana de noviembre en que, tras haber recibido una temprana llamada telefónica, comprobé la terrible desgracia que nadie quería creer.

Si volver a una vida normal es difícil, ahora lo es más, pues poner por escrito muchas emociones, refrenar otras y decir unas cuantas palabras de un joven amigo no se puede a veces soportar. Pero el compromiso estaba contraido y era obligado cumplirlo.

Tomás Quesada era un hombre de la frontera por muchos y siempre gloriosos motivos. En primer lugar, por nacimiento. Nunca renegó, sino todo lo contrario, de su bello pueblo serrano, Huelma, a las faldas de la gran Sierra Mágina, en la provincia de Jaén, casi en la raya con la de Granada. Imaginó para él miles de acciones que lo ennobleciera, rescatándolo de un sangriento olvido. El 7 de marzo de 1958 nació en el seno de una familia acomodada, siendo el menor de cuatro hermanos. Sé de su infancia por su entrañable hermano Manolo, que siempre lo tutelaba cuando ambos estudiaban en Granada en la Facultad de Filosofía y Letras. De niño ya mostró una de sus características personales e intelectuales más propias, la minuciosidad en su cotidiano quehacer y en todos sus trabajos. Asimismo, siempre estuvo preocupado por ir más allá de lo que se decía y de lo que se sabía. Fue, por eso, un lector empedernido desde pequeño y conservó este "vicio" durante toda su corta vida. Amaba asimismo el cine y otras manifestaciones artísticas. Se sentía muy orgulloso de cultivar una amistad densa con ese gran pintor y magnífica persona que es Juan Vida, autor de muchas de las portadas de sus libros. El mismo Juan me lo recordaba en esos momentos difíciles de asumir su pérdida. Pero Tomás no sólo gustaba de estos placeres "cultos", sino que conocía muy bien y llevaba en su corazón el ritmo de la tierra, del campo y de los paisajes agrestes de su infancia, volviendo siempre que podía a ellos, incluso con el deseo de devolverles la comprensión intelectual que había adquirido en tantas y tantas horas de estudio. Aprendí mucho con él, pues yo soy un hombre de la mar y la vida agrícola apenas la he vivido. Tal vez por su educación y formación en un pueblo de la sierra, tenía un entrañable sentido de la familia y de la amistad. La vida al lado de su mujer, Milagros, y de sus dos hijos, Tomás y José Manuel, era para él una necesidad primaria. Más aún, sus hermanos y padres siempre recuerdan los momentos en que todos estaban juntos, que eran continuos. Por si fuera poco, sus amigos tenían un lugar demasiado ancho en su corazón. El sentido del deber y la nobleza de sentimientos eran características intrínsecas de su 
carácter. Muchos compañeros nunca sabrán lo que ha hecho por ellos y lo que les ha favorecido sin pedir nada a cambio y sin querer que trascendiera.

Era también un hombre de la frontera, porque se dedicó a estudiarla minuciosamente con pasión y objetividad a la vez. Después de cursar brillamente la especialidad de Historia Medieval, leyó su memoria de licenciatura sobre el señorío de Huelma el 23 de enero de 198। bajo la dirección del Profesor Juan Carrasco. Primero como becario, poco después como profesor ayudante, empezó su investigación para la redacción de su tesis doctoral, que defendió con los máximos honores el 4 de julio de mil novecientos ochenta y cinco, teniendo como tribunal el formado por los profesores Valdeón, Torres Fontes, Fernández de Viana, Gan y quien estas páginas firma. Fue su director el profesor Torres Delgado, que no pudo integrar la ahora llamada comisión por la nueva normativa que entraba en funcionamiento sobre los estudios de doctorado. El tema de su tesis era más amplio, pues abarcaba toda la Serranía de Mágina, ese espacio del subbético que cierra el paso a la vega de Granada y le sirvió durante tanto tiempo de escalón defensivo. Fruto de ese trabajo surgió la publicación de dos libros, ambos en la Universidad de Granada: La Serranía de Mágina en la Baja Edad Media, y El libro de Vecindades de Huelma, ambos en 1989.

Tomás Quesada, investigador minucioso, empeñado en sacar a la luz la realidad histórica, no paró su investigación ni tras su tesis doctoral ni después de obtener, esta vez de verdad, en reñidas oposiciones la plaza de Profesor Titular de Historia Medieval de la Universidad de Granada. Continuó publicando, pero partiendo de una visión distinta. Como los hombres de la frontera, conocía bien las dos sociedades. Su formación, es cierto, era la de medievalista clásico, sabiendo manejar la documentación castellana, conociendo cómo estudiarla y editándola con pulcritud, pero su curiosidad le llevaba al otro lado de su frontera, al mundo árabe. Para ello contaba con la inestimable ayuda de Milagros Jiménez, su esposa y compañera, licenciada y doctora en Filogía Semí- tica, con quien siempre tuvo una colaboración intelectual muy fructífera. Firmaron conjuntamente un artículo que muestra bien a las claras su deseo de avanzar en el ejercicio de historiador: «En los confines de la conquista castellana: toponimia y poblamiento de los montes granadino-giennenses en el siglo XIII según la documentación cristiana». Revista del Centro de Estudios Históricos de Granada y su Reino, 6 (1992), pp. 5 I-80.

De la documentación dio también un salto a la Arqueología. Siempre he pensado que en este proceder no había una actitud sólo intelectual, sino también vital. Amaba tanto su tierra y necesitaba conocerla palmo a palmo hasta el extremo de intentar descifrar su paisaje y los vestigios de su pasado. Pero le preocupaba hacer una Historia apoyada en datos fidedignos y bien documentados. La mezcla de ambas cosas le conducía fatalmente a la Arqueología, por muy extensiva que ésta fuese. Amparado en una cierta tradición en el Departamento de Historia Medieval de la Universidad de Granada, trabajó en la temática arqueológica, siempre pertrechado de un profundo conocimiento histórico. Por eso, suscribía entusiasmado la afirmación que en Granada y en Alquife, visitando un castillo minero, ante un grupo de alumnos y de profesores hacía Riccardo Franconvich: «Sin Historia no hay Arqueología». No acudía a la Arqueología como un refugio en el que esconder escasos conocimientos históricos, como por desgracia tantas veces ha ocurrido. Antes al contrario, amante de los conocimientos fronterizos, con el riesgo que eso implica, se lanzaba al campo para responder a las dudas que se le habían planteado e iban surgiendo.

Así, obtenido el permiso correspondiente de la Junta de Andalucía, que le aprobó a partir de 199| y en años sucesivos el proyecto El poblamiento medieval de las Sierras Subbéticas de Jaén y Granada, se dispuso a hacer una minuciosa porspección con nuestra amiga y compañera Encarna Motos Guirao, arqueóloga medievalista y Profesora Titular del Departamento, y una pléyade de alumnos que empezaban a formar el embrión del obligado grupo de trabajo con que pensaba contar. Todavía recuerdo las discusiones con otros historiado- 
res y arqueólogos, más frecuentes con Vicente Salvatierra, tan unido también en formación e interés a todos nosotros, quien trabajaba en la Campiña giennense. La relación entre los jóvenes medievalistas granadinos, pues todos ellos durante un tiempo estuvieron integrados en el mismo Departamento, era muy cordial y limpia, aun cuando sus investigaciones a veces se tocaban. No es extraño, no sólo porque soplababan nuevos aires que traían una frescura y otras formas de ver los problemas, sino también porque con un hombre como Tomás Quesada eran imposibles las rencillas. Siempre lo hemos considerado como impulsor de una paz absolutamente necesaria para el contraste de ideas y opiniones necesariamente diversas, sin que por ello renunciase a su firme e insobornable opinión.

Fruto de una tarea tan ingrata como es la prospección, considerada irrelevante por tantos historiadores e incompleta por muchos arqueólogos, sin duda todos ellos miopes, surgieron estudios de verdadero interés: «El poblamiento medieval en las Sierras Subbéticas de Jaén y Granada. El caso de Sierra Mágina». Studia Historica. Historia Medieval, IX (I99 |), pp. |59-|8|, y «Formas de poblamiento en un área rural de al-Andaluss: el valle del río Jandulilla». Arqueología y Territorio Medieval, II (1994), pp. 5-23.

En realidad, este proyecto de investigación sentó las bases para llevar a cabos estudios aún más densos, en los que combinaba sus muchos conocimientos de la documentación castellana con los datos de las fuentes arqueológicas y los que arrancaba con gran esfuerzo y entusiasmo a los textos árabes. Es el caso de su libro: El paisaje rural de la Campiña de Jaén en la Baja Edad Media según los «Libros de las Dehesas». Jaén, Universidad, 1994, que ya reseñé en esta misma revista. En esas fechas ya disfrutaba de un proyecto de la D.G.I.C.Y T. del Ministerio de Educación y Ciencia, sobre Las salinas de Andalucía Oriental en la Edad Media. Estudio histórico y arqueológico. Siempre he pensado y se lo dije en múltiples ocasiones que le permitiría mostrar su densa formación y su buen quehacer. El tema era de de una gran dificultad, pero estaba más que preparado para desa- rrollarlo. Entre otras cosas, se percató, a raíz de su investigación en este campo, de la necesidad de acudir a la Etnología y a la Etnografía, lo que le llevó a establecer una relación muy intensa con el Centro de Investigaciones Etnológicas Angel Ganivet, de la Diputación Provincial de Granada, dirigido por el infatigable e insobornable José Antonio González Alcantud. Así surgió la idea de rodar un video, que sólo después de la muerte de Tomás Quesada, como un homenaje póstumo a él, ha visto la luz. Se pensó que era una buena ocasión para presentarlo el Congreso Mundial de Historia de la Sal, auspiciado por la Comisión Internacional de Historia de la Sal (C.I.H.S.), celebrado en Granada en septiembre de 1995. No pudo ser por problemas ténicos, pero su esfuerzo, que fue notable, se ve reflejado en el resultado final.

Miembro de la C.I.H.S., coorganizador de ese congreso, participó en el mismo y ha escrito en su revista, el Journal of Salt History. Su interés por el tema de la historia de la sal y su preparación hacían presagiar una investigación densa y excelente. Una declaración de principios se contiene en el artículo que ambos firmamos: «Las salinas de Andalucía Oriental en época medieval. Planteamientos generales y perspectivas de investigación». Journal of Salt History, II (1994), pp.|44-I69, pero se desarrolla en otros que han visto la luz bien poco antes 0 desgraciadamente al poco de su fallecimiento, de los que citaremos sólo: «El agua salada y las salinas», en El agua en la agricultura de al-Andalus. Madrid-Barcelona, 1995, pp. |3|-|4|, y «Las salinas de interior de Andalucía oriental: ensayo de identificación». Actas del II Coloquio de Historia y medio físico. Agricultura y regadío en al-Andalus. Granada, 1996, pp. 317-333, que me fue entregado por el editor la tarde antes de su muerte, sin que alcanzara a verlo.

Estoy seguro que cuantos lo conocieron suscribirán lo que ya he escrito acerca de su capacidad como investigador y habrán lamentado su desaparación como persona. Todas sus cualidades intelectuales y humanas se reflejaban de manera especial en sus clases. No he tenido, lógicamente, la posibilidad de asistir a las mismas, pero sé del aprecio que le tenían los 
alumnos que pasaron por ellas, e incluso diré que una admiración de la que sólo gozan los buenos profesores. Y es que Tomás Quesada no sólo quería aprender para conocer, sino también para enseñar. Por eso, los estudiantes en reiteradas ocasiones lo señalaron como uno de los mejores de cuantos impartían clases en la Facultad. Hombre serio, alejado de las vanidades y halagos, como lo ha calificado Crsitóbal Torres, su profesor y maestro, ocultaba estas opiniones a sus amigos y compañeros, que las conocíamos por terceras personas.

No tuvo reparos en compartir cuanto sabía y en organizar seminarios, reuniones y encuentros de todo tipo para ampliar los horizontes de la Universidad de Granada. Ahí están los trabajos recopilados por nosotros dos sobre el feu- dalismo mediterráneo, en el que escriben historiadores tan importantes como Pierre Toubert o Chris Wickham, por citar sólo a dos de ellos y que lleva el siguiente título: Los orígenes del feudalismo en el mundo mediterráneo. Granada, Universidad, 1994.

En realidad Tomás aprendió de todos y todos hemos aprendido de él, como cabe esperar en la vida universitaria a la que se entregó al mismo tiempo que a su familia, dejando un vacío que será imposible de rellenar. Una buena parte del futuro del medievalismo granadino se ha ido con él.

Antonio MALPICA CUELLO.
Universidad de GRANADA 